\title{
REFLEXÕES SOBRE POSSÍVEIS CRITÉRIOS DE QUALIDADE DA ESCOLA EM TEMPO INTEGRAL
}

HEIKE SCHMITZ MARIA CELESTE REIS FERNANDES DE SOUZA

\section{RESUMO}

Este texto se insere no cenário de debates sobre a educação integral/ tempo integral, que tem sido objeto de atenção no Brasil nos últimos anos. A análise problematiza os limites das atuais avaliações externas de larga escala para verificar a qualidade da escola em tempo integral. 0 objetivo do artigo é refletir sobre uma possível sistematização de critérios de qualidade da escola em tempo integral, com vistas a avaliar a sua eficácia. Os argumentos foram construídos a partir de uma revisão da literatura científica, de análise documental e de análise secundária de pesquisas, predominantemente de cunho qualitativo, e toma como referência as contribuições de Holtappels, em diálogo com estudos sobre a ampliação da jornada escolar no Brasil. As conclusões apontam que o modelo apresentado pode contribuir como ferramenta heurística para nortear o desenvolvimento organizacional da escola.

PALAVRAS-CHAVE AVALIAÇÃO DA EDUCAÇÃO • EDUCAÇÃO EM TEMPO INTEGRAL・EDUCAÇÃO INTEGRAL・ QUALIDADE. 


\section{REFLEXIONES SOBRE POSIBLES CRITERIOS DE CALIDAD DE LA ESCUELA EN TIEMPO INTEGRAL}

RESUMEN

Este texto se inserta en el escenario de debates sobre la educación integral/tiempo integral, que ha sido objeto de atención en Brasil en los últimos años. El análisis problematiza los límites de las actuales evaluaciones externas de gran escala para verificar la calidad de la escuela en tiempo integral. El objetivo del artículo es el de reflexionar sobre una posible sistematización de criterios de calidad de la escuela en tiempo integral, con miras a evaluar su eficacia. Los argumentos fueron construidos a partir de una revisión de la literatura científica, del análisis documental y del análisis secundario de investigaciones, predominantemente de cuño cualitativo, y toma como referencia las contribuciones de Holtappels, en diálogo con estudios sobre la ampliación de la jornada escolar en Brasil. Las conclusiones señalan que el modelo presentado puede contribuir como herramienta heurística para orientar el desarrollo organizativo de la escuela.

PALABRAS CLAVE EVALUACIÓN DE LA EDUCACIÓN • EDUCACIÓN EN TIEMPO

INTEGRAL・EDUCACIÓN INTEGRAL・CALIDAD.

\section{REFLECTIONS ON POSSIBLE QUALITY CRITERIA FOR FULL-TIME SCHOOLS}

ABSTRACT

This paper focuses on the debates concerning full time-education, which has been subject of attention in Brazil in recent years. The analysis discusses the limits of current large-scale external assessments to check the quality of full-time schools. The objective of this article is to reflect on a possible criteria systematization concerning the quality of full-time schools, in order to assess their effectiveness. The arguments were based on a review of the scientific literature, documentary analysis and secondary research analysis, mainly of qualitative nature, and take as reference Holtappels' contributions, as well as studies about the expansion of the school day in Brazil. The findings indicate that the model presented may contribute as a heuristic tool to guide the schools' organizational development.

KEYWORDS ASSESSMENT OF EDUCATION • FULL-TIME EDUCATION • INTEGRAL EDUCATION • QUALITY. 


\section{INTRODUÇÃO}

Nos últimos anos, o debate sobre a educação integral e o tempo integral tem novamente ganhado centralidade no campo educacional. Diferentes dispositivos legais contribuíram para isso, cujo marco inicial é a Constituição Federal de 1988, culminando, recentemente, no Plano Nacional de Educação para o decênio 2015-2024, que estabelece uma meta específica para a ampliação da jornada escolar. Esse debate não se constitui uma novidade, posto que, historicamente, já foram vivenciadas no país experiências de educação integral, em tempo integral, que remontam ao início do século anterior com os movimentos anarquista, integralista e escolanovista, sendo este último o movimento inspirador, na atualidade, do Programa Mais Educação (PME), do Ministério da Educação (MEC), cuja intenção é induzir políticas de ampliação da jornada escolar.

No entanto, mesmo assim, e diante da centralidade atual, podemos constatar, tanto em termos da prática pedagógica como da pesquisa educacional, um campo aberto ao debate. No plano da prática pedagógica, as inquietações se apresentam na própria compreensão dos termos "educação 
integral”|“tempo integral”|“jornada escolar ampliada”. Eles contemplam os aspectos legais e apresentam dilemas específicos sobre a organização das experiências, tais como: turno ou contraturno; seleção de estudantes ou universalização; organização do currículo; organização dos tempos e espaços escolares; professores ou voluntários para o desempenho das atividades no tempo ampliado; aproximação com a cidade ou experiências mais centradas na escola, entre outros desafios.

No campo da pesquisa educacional, essas temáticas têm sido, na última década, objeto de diversas análises, contemplando, entre outros, aspectos históricos e legais, como as contribuições de Coelho e Cavaliere (2002) e Moll (2012). Buscando compreender os dilemas expostos acima, foram realizadas pesquisas de natureza quantitativa, com a finalidade de mapear o panorama das propostas de ampliação da jornada escolar (BRASIL, 2010a; 2013a), e pesquisas de natureza qualitativa, como forma de estudo de caso, que analisam propostas específicas de ampliação da jornada escolar (BRASIL, 2010b; UNIVERSIDADE FEDERAL DE MINAS GERAIS - UFMG, 2012).

Entretanto, nesse cenário, uma questão nos pareceu lacunar e é para a qual voltamos as nossas atenções neste artigo: uma sistematização de critérios de qualidade da escola em tempo integral, imprescindíveis para, posteriormente, avaliar a sua eficácia. Os argumentos foram construídos a partir de uma revisão da literatura científica, de análise documental e de análise secundária de pesquisas, predominantemente, de cunho qualitativo.

O texto encontra-se organizado em três seções: a primeira seção tem como propósito contribuir para a compreensão da educação integral e tempo integral, contemplando aspectos históricos, legais e características conceituais, pois desses podem se deduzir os benefícios esperados e, consequentemente, critérios de qualidade da escola em tempo integral; a segunda seção coloca em discussão se, diante dessas expectativas articuladas à escola em tempo integral, a eficácia da escola em tempo integral pode ser avaliada por teste de rendimento escolar, e problematiza quais aspectos da educação integral em tempo integral não podem ser negligenciados 
1 A esse respeito, sugerimos conferir a literatura que aborda experiências históricas de ampliação da jornada escolar: Branco (2012); Coelho e Cavaliere (2002); Coelho (2009a 2009b); Gadotti (2009) em uma avaliação; como decorrência das discussões das seções anteriores, na terceira seção é apresentado o modelo de qualidade da educação em tempo integral de Heinz Günter Holtappels (2009), como base para discutir uma sistematização de possíveis critérios de qualidade.

\section{EDUCAÇÃO INTEGRAL EM TEMPO INTEGRAL}

A educação integral em tempo integral não é uma ideia recente no Brasil. Já no início do século passado, os defensores da Escola Nova consideraram a ampliação dos objetivos de ensino e do tempo que o aluno permanece diariamente na escola uma estratégia adequada para melhorar a qualidade da educação pública. Referências como Anísio Teixeira, Paulo Freire, Darcy Ribeiro, entre outros, argumentaram a favor da educação integral e do tempo integral e se dedicaram à formulação e implementação de políticas em prol dessas práticas. ${ }^{1}$

A educação integral é, desde 1988, objetivo constituído no Brasil. A Constituição da República Federativa do Brasil de 1988 (BRASIL, 1988), e coerentemente a Lei n. 8.069, de 13 de julho de 1990, que dispõe sobre o Estatuto da Criança e do Adolescente (BRASIL, 1990), bem como a Lei n. 9.394, de 20 de dezembro de 1996, que estabelece as diretrizes e bases da educação nacional (BRASIL, 1996), anunciam, como objetivo da educação, o desenvolvimento pleno da pessoa.

No que diz respeito à educação em tempo integral, a Lei de Diretrizes e Bases da Educação Nacional (LDBEN/1996) prevê, para a educação infantil e o ensino fundamental, nos arts. 31 e 34, respectivamente, uma jornada diária ampliada. No art. 31 define-se como regra comum um "atendimento à criança de, no mínimo, quatro horas diárias para o turno parcial e de sete horas para a jornada integral", e no art. $34, \S 2^{\circ}$, declara-se, para o ensino fundamental, que esse "será ministrado progressivamente em tempo integral, a critério dos sistemas de ensino" (BRASIL, 1996). Especifica-se, mais uma vez, com a implementação da Lei n. 11.494, de 20 de junho de 2007, que regulamenta o Fundo de Manutenção e Desenvolvimento da Educação Básica e de Valorização dos Profissionais da Educação (Fundeb), ao estabelecer para os fins de distribuição de recursos públi- 
cos, uma definição da educação escolar em tempo integral (BRASIL, 2007a). Compreende-se, como assim explicita o art. $4^{\circ}$ do Decreto n. 6.253, de 13 de novembro de 2007, que dispõe sobre o Fundeb, como

\section{[...] educação básica em tempo integral a jornada escolar com duração igual ou superior a sete horas diárias, duran- te todo o período letivo, compreendendo o tempo total que um mesmo aluno permanece na escola ou em ativida- des escolares. (BRASIL, 2007b)}

No cumprimento a esses dispositivos legais, anteriormente citados, destaca-se o papel desempenhado pelo PME, instituído pela Portaria Normativa Interministerial n. 17, de 24 de abril de 2007, que "visa fomentar a educação integral de crianças, adolescentes e jovens, por meio do apoio a atividades socioeducativas no contraturno escolar" (BRASIL, 2007c).

Com efeito, a partir da implementação do PME, há um incremento das matrículas em tempo integral. Se em 2009 havia 945.044 estudantes em tempo integral no ensino fundamental, no ano de 2014 esse número chega a 1.666.011 estudantes, conforme dados divulgados pelo Instituto Nacional de Estudos e Pesquisas Educacionais Anísio Teixeira (Inep), relativos ao Censo Escolar da Educação Básica. ${ }^{2}$

Contudo, não se trata apenas de se preocupar em alcançar metas quantitativas. Exige-se, também, uma nova configuração do trabalho pedagógico realizado nas escolas que funcionam em tempo integral. Cavaliere (2009), contribuindo para a discussão sobre a questão da permanência das crianças e dos adolescentes no espaço escolar, distingue, em sua análise, duas vertentes que estão se configurando no país nas propostas de ampliação do tempo diário:

[...] uma que tende a investir em mudanças no interior das unidades escolares, de forma que possam oferecer condicões compatíveis com a presença de alunos e professores em turno integral, e outra que tende a articular instituições e projetos da sociedade que ofereçam atividades aos alunos no turno alternativo às aulas, não necessariamente no espaço escolar, mas, preferencialmente, fora dele. (CAVALIERE, 2009, p. 52) 
3 Por turno único em tempo integra compreende-se organização das atividades diárias sem divisão em ensino regular e atividades extraclasse. Em outras palavras, trata-se de um turno que alterna atividades de ensino regular e extraclasse conforme razões pedagógicas (teoria/ prática, tensão/relaxamento, etc.) contemplando na escola, inclusive, a alimentação escolar. Por modelo de contraturno compreende-se, aquele em que os alunos frequentam a oferta extraclasse (antes ou depois) após o turno do ensino regular. Aqu existe tanto a possibilidade de eles permanecerem na escola para almoçar ou voltarem para casa para, depois do almoço, retornarem à escola.

4 O Programa Segundo Tempo (PST), ação intersetorial do Governo Federa integrando Esporte e Educação, oferece múltiplas vivências esportivas no contraturno escolar, por meio do Programa Mais Educação do Ministério da Educação. A integração do Programa Segundo Tempo e do Programa Mais Educação é chamada de PST na Escola. Disponível em: <http://www2.esporte.gov.br/snee/ segundotempo/maiseducacao/ default.jsp.> Acesso em: 17 nov. 2015
No levantamento realizado em 2012 em âmbito nacional, 76\% dos gestores estaduais/municipais do PME que participaram da pesquisa confirmaram reformas no espaço das escolas das suas redes, mas $17,8 \%$ informaram que não houve investimentos em reformas de infraestrutura, e 3,5\% não souberam informar mudanças nesse quesito. Dos 212 municípios participantes do estudo, cujas escolas aderiram ao PME, 83\% organizaram também atividades extraclasse em espaços das cidades, por vezes, em decorrência da fragilidade estrutural das escolas (BRASIL, 2013a), e não como opção pedagógica de apropriação dos espaços das cidades.

O melhor aproveitamento de espaços escolares e também de espaços fora desse ambiente implica reflexões sobre como organizar o trabalho pedagógico. Podem ser encontradas, recentemente no Brasil, diferentes propostas que se organizam em um turno único, que são minoria, ou no contraturno ${ }^{3}$ escolar, que correspondem à maioria das propostas $(80,1 \%)$, como mostra o levantamento nacional realizado em 2008 (BRASIL, 2010a). As propostas no contraturno, de modo geral, não alcançam a todos os estudantes (BRASIL, 2010a, 2010b; MOLL, 2012).

Esse arcabouço legal e de experiências traz, para o repertório linguístico no campo da educação, diversas expressões de modo algum sinônimas. O próprio termo "educação integral", bem como "jornada ampliada", "tempo ampliado", "educação integrada”, "educação integral/integrada”, "escola em tempo integral", "contraturno", entre outros, como os que trazem as marcas de projetos locais, ou programas governamentais, como o Programa Segundo $\mathrm{Tempo}^{4}$ e o Programa Mais Educação.

Embora não sejam sinônimos, tais termos carregam, em seu significado, a compreensão sobre a ampliação da jornada escolar do ponto de vista legal, como horas a mais na escola. Entretanto, é preciso atenção ao fato de que "Educação integral em tempo integral já evidencia algo relevante, pois não confunde educação de tempo integral, ou extensão do tempo de escolaridade, com educação integral" (PARO, 2009, p. 14, grifos do autor).

Assim, o tempo a mais passado diariamente na escola nem sempre leva a uma educação integral, principalmente 
quando se repete nesse período o que a escola já fazia: mesmo currículo, mesmas práticas, mesmo modo de organização e distribuição do tempo. Ou seja, seria a ampliação de um tempo do mesmo, um período a mais na escola com repetição de práticas e conteúdos transmitidos sem se preocupar com a formação integral do aluno (PARO, 2009; MOLL, 2012).

Contudo, parece plausível pressupor que a educação integral que compreende a formação multidimensional do sujeito nos aspectos cognitivos, culturais, estéticos, corporais, éticos e cidadãos requer mais tempo, ou seja, um tempo integral (COELHO; CAVALIERE, 2002; COELHO, 2009a, 2009b; MAURÍCIO, 2014).

Além disso, a ampliação do tempo escolar abarca diversos interesses, necessidades e propósitos. Uma análise das diferentes propostas, ou dos objetivos múltiplos do próprio PME, mostra que se espera da educação integral/tempo integral, como redesenho de política educacional, o cuidado e a proteção infanto-juvenil, a redução das taxas de evasão escolar, a elevação do Índice de Desenvolvimento da Educação Básica (Ideb), ${ }^{5}$ a ampliação do acesso à cidade e a ampliação das oportunidades educacionais. ${ }^{6}$

Além das diferenças de defesa sobre a necessidade de ampliação do tempo da jornada escolar diária, as diferentes interpretações mobilizam formas diversas de organização de propostas, como podemos conferir na produção acadêmica. Estudos brasileiros destacam as Escolas-Classe/Escolas-Parque, concebidas por Anísio Teixeira nos anos 1950, analisam experiências dos Centros Integrados de Educação Pública (Cieps), nos anos de 1980-1990, concebidos por Darcy Ribeiro (COELHO; CAVALIERE, 2002), e refletem sobre experiências de tempo integral nos últimos anos, como organizadas em uma jornada escolar diária de turno e contraturno, ou em um único turno, mesclando atividades do ensino regular e de atividades extraclasse (BRASIL, 2010a, 2010b; COELHO, 2009b; CORÁ; LOSS; BEGNINI, 2012; FUNDAÇÃO ITAÚ SOCIAL, 2006, 2011; LOMONACO, 2013; MOLL, 2012).

O arcabouço teórico e legal considera que o tempo a mais na escola é condição fundamental para a aprendizagem, sendo essa uma das questões centrais na proposição da ampliação da
5 Criado em 2007, o índice abarca dois indicadores básicos para a qualidade da educação: fluxo escolar e desempenho nas avaliações. Para maiores informações sobre o Ideb. conferir o Portal Ideb, disponível em: $<$ http://portal.inep.gov.br/web/portalideb>. Acesso em: 30 out. 2015.

6 Documentos disponíveis em: $<$ http://educacaointegral.mec.gov. br/>. Acesso em: 20 out. 2015. 
jornada escolar: o tempo a mais na escola deve garantir, como prioridade, novas oportunidades de aprendizagem.

A aprendizagem é parte constitutiva dos direitos educacionais e condição básica para o acesso a outros direitos: sociais, econômicos, civis e políticos. Ir à escola significa a garantia do direito ao acesso, mas também a garantia do direito ao pleno desenvolvimento pessoal e à aprendizagem, conforme estabelecido na Constituição Federal (BRASIL, 1988), no Estatuto da Criança e do Adolescente (ECA) (BRASIL, 1990) e nas Diretrizes Curriculares Nacionais para a Educação Básica (BRASIL, 2013b). Nesse sentido, considera-se pertinente um olhar mais atento sobre o que acontece no tempo integral com relação às aprendizagens dos alunos.

\section{A EDUCAÇÃO EM TEMPO INTEGRAL E SEU EFEITO NA APRENDIZAGEM DO ALUNO}

Compreendendo que a eficácia da escola se evidencia na promoção da aprendizagem do aluno e que a eficiência da escola, entre outros, se mostra no tempo dedicado para alcançar tal aprendizagem, levanta-se a questão: Quais os efeitos da frequência do aluno à escola em tempo integral sobre a sua aprendizagem?

Na revisão da literatura empreendida em nossa análise, encontramos três pesquisas, como forma de estudo de caso, que buscam compreender a correlação entre ampliação do tempo e aprendizagens. Na primeira, realizada por Castro e Lopes (2011), que tem como objeto a experiência de implantação da Escola de Tempo Integral no Estado de São Paulo em 2006, as autoras analisam, entre outros aspectos, dados de desempenho escolar de estudantes no Sistema de Avaliação do Rendimento Escolar do Estado de São Paulo (Saresp), no período de 2005 a 2007. Os resultados dos estudantes nas habilidades de leitura, escrita e matemática, verificadas no Saresp, não se apresentam melhores do que os apresentados por estudantes em tempo parcial. Em algumas escolas há, inclusive, com o tempo integral, decréscimo no desempenho.

O segundo estudo, desenvolvido por Coelho (2012), analisa os relatos de alunos dos anos iniciais do ensino 
fundamental sobre suas aprendizagens em tempo integral, e conclui que tanto em uma como em outra forma de organização do tempo (para todos, ou para alguns), há indicativos de ampliação das aprendizagens. Entretanto, a autora problematiza as atividades que acontecem no contraturno por meio de parcerias e o que se compreende por educação integral e aprendizagem do aluno. Para a autora, corre-se o risco de que a escola assuma, no tempo integral, um lugar de transitoriedade, em um caráter mais assistencial e protetor, o que pode comprometer, visivelmente, a sua função de ensino.

Por fim, o estudo realizado por Souza (2015), que visava a compreender a relação que estudantes dos anos finais do ensino fundamental estabelecem com o saber e com a escola, na qual permanecem por oito horas diárias, em um turno único, conclui que não há uma correlação estreita entre ampliação do tempo de escola e aprendizagem. Para que a ampliação do tempo faça diferença, no tocante à aprendizagem, há as condições gerais da oferta (currículo, infraestrutura, incorporação de atividades que contemplem o corpo, a arte e o movimento, etc.), mas também há a qualidade da aula e a mobilização do estudante para o aprender. Embora se correlacione com fatores externos, a mobilização é um fator interno e, como ressaltam os próprios estudantes, não importa o tempo de permanência na escola, pois o estudante deve desejar aprender. Cabe à escola, segundo a autora, produzir efeitos de mobilização e, nesse sentido, o tempo pode favorecer um maior conhecimento do estudante como sujeito social (pertencimento a um grupo cultural) e sujeito singular.

Outros estudos, nos quais a correlação tempo e aprendizagem comparece como um dos itens contemplados para se medir os impactos da ampliação da jornada escolar, foram os realizados pela Fundação Itaú Social. Um desses estudos é uma análise da literatura sobre educação integral/tempo integral em diferentes países, e que se sustenta em resultados de pesquisas que utilizaram metodologia quantitativa, cujo foco foi a questão da aprendizagem e da equidade. ${ }^{7} \mathrm{~A}$ conclusão do estudo aponta que, de modo geral, a ampliação do número de horas se associa ao maior desempenho
7 Foram analisados resultados de pesquisa divulgados nos últimos dez anos, em periódicos e anais de eventos com classificação igual ou superior a B2 pela Qualis/Capes (nacionais) ou A2 (internacionais). 
escolar. Entretanto, considerando a diferença entre as propostas de tempo integral, conclui que não é possível uma resposta definitiva sobre a eficácia do tempo integral na melhoria do desempenho dos estudantes:

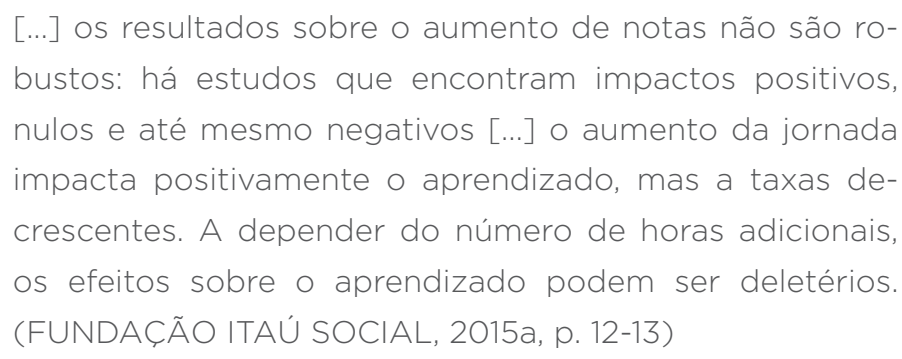

Foi também objeto de análise o PME. Um dos objetivos do estudo foi avaliar a sua eficácia na elevação do aproveitamento escolar. $\mathrm{O}$ foco de análise foram as dimensões de aprendizagem mensuradas pela nota na Prova Brasil. As conclusões do estudo apontam que:

Não foi possível encontrar impactos do programa sobre
o desempenho médio das escolas em português nem so-
bre a taxa de abandono. Tanto no curto quanto no médio
prazo, houve impacto negativo do programa sobre o de-
sempenho médio das escolas em matemática. Os efeitos
negativos em matemática, em dada escola, reduzem-se
com o passar do tempo. Os efeitos negativos em matemá-
tica são de menor magnitude para as escolas que aderiram
ao programa mais recentemente (2010), e ficam restritos
ao 5 o ano. (FUNDAÇÃO ITAÚ SOCIAL, 2015b, p. 15)

O conjunto dos estudos apresentados nesta seção evidencia que, aparentemente, não é uma questão simples responder quais os efeitos da escola em tempo integral sobre as aprendizagens dos alunos, especialmente quando se considera que a educação integral, em tempo integral, enfatiza, seja no contraturno ou em um turno único, no currículo, aprendizagens cognitivas, estéticas, corporais, culturais aprendizagens que deveriam integrar o repertório de análise sobre a correlação tempo/aprendizagem.

De modo geral, a questão do desempenho da instituição de ensino tem sido avaliada no Brasil por meio de avaliações 
sistemáticas de sistemas educacionais como o acima mencionado Saresp ou, em âmbito nacional, por exemplo, a Prova Brasil, cujos resultados constituem inclusive um indicador que compõe o Ideb.

Seria, pois, o Ideb um bom indicador de análise do impacto do tempo integral sobre o desempenho escolar do aluno? Diante do fato de que o Ideb utiliza, como base de cálculo, dados sobre a aprovação escolar, por meio do Censo Escolar, e as médias de desempenho nas avaliações do Inep (Prova Brasil ou Saeb) obtidas pelos estudantes ao final da $1^{\text {a }}$ e $2^{\mathrm{a}}$ etapas do ensino fundamental e $3^{\circ}$ ano do ensino médio, e, além desse diagnóstico, apresenta uma projeção de metas para a melhoria da qualidade da educação, podemos encontrar três possíveis respostas a essa pergunta.

Uma primeira resposta diz respeito à questão do fluxo escolar. Os fenômenos da evasão e repetência tornam-se alvos de atenção na educação brasileira, de modo mais acentuado, a partir da década de 1980 , no processo de democratização do ensino fundamental e da busca por sua universalização. A redução da taxa de evasão e da repetência é, como já revela a definição do público-alvo da ampliação do tempo de escola, objeto de atenção do PME:

Estudantes que apresentam defasagem idade/ano; Estudantes das séries finais da $1^{\underline{a}}$ fase do ensino fundamental (4ํe/ou 5ํanos), onde existe maior saída espontânea de estudantes na transição para a $2^{\text {a }}$ fase; Estudantes das séries finais da $2^{\text {a }}$ fase do ensino fundamental ( $8^{\circ}$ e/ou 9aos), onde existe um alto índice de abandono após a conclusão; Estudantes de anos/séries onde são detectados índices de evasão e/ou repetência. (BRASIL, 2014a, p. 18)

Nesse sentido, propõe-se, por meio do PME, a oferta de atividades de acompanhamento pedagógico, artísticas, culturais e de lazer, com vistas a propiciar, a esse público, um repertório de experiências que equalize diferenças com relação a aprendizagens, bem como amplie o acesso a experiências a um grupo que, de certo modo, fica delas alijado (MOLL, 2012).

Assim, do ponto de vista de tornar a escola mais atrativa e potencializar aprendizagens, o tempo integral pode 
8 A Prova Brasil avalia Habilidades em Língua Portuguesa (foco em leitura) e Matemática (foco na resolução de problemas). Informações disponíveis em: <http://portal.inep.gov.br/web/ saeb/aneb-e-anresc >. Acesso em: 2 jul. 2016. Conferir, também, a Portaria n. 174 de 13 de maio de 2015 (BRASIL, 2015). encontrar, no Ideb, um indicador importante para analisar a permanência e o fluxo escolar dos alunos. Ou seja, o tempo integral propicia mais tempo do aluno na escola, com vistas à conclusão do ensino fundamental e médio sem repetência, favorecendo, assim, o sucesso na trajetória escolar e, dessa forma, a eficácia e eficiência da escola.

Uma segunda possibilidade da utilização desse indicador é um pouco mais limitada. Ao se apoiar na Prova Brasil, que avalia o desempenho de estudantes da $4^{\mathrm{a}}$ série $/ 5^{\circ}$ ano e da $8^{\mathrm{a}}$ série $/ 9^{\circ}$ ano do ensino fundamental, ${ }^{8}$ o Ideb contribuirá para compreender conhecimentos específicos de uma parcela do currículo (Português e Matemática), e a educação integral em tempo integral pressupõe um currículo que abarque a multidimensionalidade do sujeito, como discutimos anteriormente. Assim, outras competências e habilidades importantes, que se pretende desenvolver por meio da oferta pedagógica diversificada em tempo integral, ficarão fora da análise, o que supõe a busca por outros indicadores de avaliação, que envolvem aspectos de difícil padronização, por exemplo, as artes e o acesso a experiências culturais.

Contudo, diante do fato de que a avaliação de capacidades linguísticas e do raciocínio lógico não se limita ao ensino de disciplinas como Português e Matemática, a oferta da educação em tempo integral é uma oportunidade de quebrar um comportamento não desejado, como o treino e a preparação de estudantes para provas com perguntas fechadas visando à melhoria de resultados na Prova Brasil, por exemplo, e estimular a compreensão de que as capacidades linguísticas e de raciocínio lógico estão sendo desenvolvidas em todas as atividades escolares.

Como a política nacional de avaliação não propõe uma verificação de conteúdos cognitivos, mas sim uma avaliação de competências e capacidades dos estudantes, o aumento e a diversificação de oportunidades de aprendizagem ofertados em uma jornada escolar ampliada configuram uma estratégia interessante para que o estudante possa descobrir diversos caminhos para adquirir as denominadas capacidades-chave, como resolução de problemas, leitura e interpretação de textos, estabelecimento de relações lógico-discursivas, 
compreensão de dados matemáticos em contextos informativos, entre outras.

A terceira possibilidade se relaciona às metas que são estabelecidas para desenhar uma trajetória da melhoria da educação brasileira, com o objetivo de alcançar a média da qualidade dos países que participam da Organização para a Cooperação e Desenvolvimento Econômico (OCDE), já que os resultados do Brasil ficaram aquém do desejado nas avaliações do Programa Internacional de Avaliação de Alunos (Pisa; sigla inglesa). Uma das estratégias para melhorar o desempenho escolar é investir na ampliação da jornada escolar, como ocorreu, por exemplo, na Alemanha, depois de ter constatado que os resultados do Pisa estavam abaixo das expectativas (ROLLETT, 2014). Assim, a busca pela melhoria do Ideb se alia à ampliação da jornada escolar, como podemos conferir nas metas estabelecidas no Plano Nacional de Educação (PNE) (BRASIL, 2014b).

Como efeito dessa avaliação externa, há uma cultura de busca de melhoria do Ideb, com maiores investimentos educacionais por meio do Ministério da Educação, dos estados e dos municípios de modo geral. Essa cultura pode favorecer a melhoria desse Índice, que tem crescido no país, como demonstram as projeções e o alcance das metas divulgadas no site do Inep. ${ }^{9}$

Referências do Ideb ainda têm sido pouco utilizadas para análises relativas à ampliação da jornada escolar. Por exemplo, no mapeamento das propostas de ampliação da jornada escolar no país, ao se apresentar cada proposta analisada (BRASIL, 2010b), situa-se o Ideb dos municípios, e são apontadas melhorias, como fator positivo da ampliação do tempo de escola. Entretanto, ao analisarmos mais detidamente tais conclusões e as propostas estudadas, constata-se que algumas são anteriores ao Ideb apresentado. Mas, além dessa questionável correlação entre participação do Programa Mais Educação e melhoria no Ideb, vale ressaltar que essa correção não substitui uma análise de causa-efeito. E, nesse caso, nem se pode comprovar uma relação de causa-efeito pela "juventude" das propostas analisadas. Ou seja, na época da realização do estudo não era possível analisar os efeitos
9 Disponível em: <http:// educacaointegral.mec.gov.br/> Acesso em: 18 out. 2015 
da ampliação da jornada escolar, porque os alunos matriculados em tempo integral não frequentaram um período considerável para poder pressupor mudanças na aprendizagem correlacionadas ao tempo de escola.

Para que os resultados do Ideb sejam utilizados como ferramenta de pesquisa sobre a efetividade do tempo integral para melhoria da aprendizagem, pode-se aventar a possibilidade de acompanhamento dos resultados daqueles estudantes que participam na oferta da educação em tempo integral, por meio de cruzamento do seu número de registro no Inep na Prova Brasil e no PME (ou outras políticas públicas em prol da educação em tempo integral). Dessa forma, poderiam, além do cálculo do Ideb da escola, ser aproveitados os resultados da Prova Brasil, para comparar o rendimento dos alunos que frequentam a escola em tempo integral com aqueles que a frequentam em tempo parcial.

Além disso, acompanhando o desenvolvimento da aprendizagem dos alunos matriculados em tempo integral, e comparando-o com o dos alunos da mesma escola que a frequentam em tempo parcial, é possível responder: Quais os efeitos da frequência do aluno na escola em tempo integral sobre a sua aprendizagem? A partir da base de dados, disponibilizada pelo Inep sobre o desempenho de estudantes em Português e Matemática, seria possível também realizar pesquisas longitudinais, comparando os resultados do mesmo aluno do $5^{\circ}$ ano com os resultados do $9^{\circ}$ (e do $3^{\circ}$ ano no ensino médio), para analisar a aprendizagem do aluno, mas também para identificar o impacto do efeito da instituição de ensino, correlacionando com as condições da escola e da prática escolar. A partir disso, seria possível, inclusive, identificar se o efeito da educação em tempo integral cresce em relação ao número de anos em que o aluno frequenta a escola em tempo integral, e identificar condições favoráveis para tal crescimento, analisando, por exemplo, a existência de efeitos diferenciados entre gênero, a faixa etária.

O que levantamos como discussão é que o Índice é uma ferramenta importante que, inclusive, poderia ser ainda mais explorada, mas que por si só não consegue analisar o efeito escola, e nem serve efetivamente para correlacionar 
o fator "tempo integral" e aprendizagem pelo próprio espectro do que se compreende como aprendizagem no tempo integral envolvendo outros aspectos, além dos cognitivos, como ampliação das possibilidades culturais, maior apropriação dos espaços da cidade, vivências corporais (esporte e lazer) e participação cidadã.

Por isso, Cavaliere (2007) evoca o tempo como um dos fatores a serem analisados na qualidade da escola pública em tempo integral. A autora argumenta que o tempo escolar é um elemento que tem comparecido nas pesquisas sobre o efeito escola, ou seja, na capacidade da escola de conseguir elevar o nível de aprendizagem dos alunos e de atuar de maneira equitativa, de modo a igualar, em termos de aprendizagem, a diversidade de alunos que acolhe (BRESSOUX, 2011). Nos estudos, o tempo é analisado do ponto de vista do calendário escolar (número de dias anuais, carga horária semanal, duração diária, períodos de férias). Os resultados desses estudos demonstram que "não há uma associação automática entre mais tempo e melhor desempenho ou vice-versa" (CAVALIERE, 2007, p. 1.019). Portanto, quantidade de tempo não significa, necessariamente, melhoria na aprendizagem.

As reflexões sobre o Ideb e as contribuições teóricas elencadas nesta seção possibilitam concluir que a escola em tempo integral pode se valer dos resultados do Ideb para analisar os efeitos da ampliação da jornada, mas também precisa responder a outras questões que se correlacionam à sua função de ensinar. Desse modo, deve considerar os objetivos da ampliação da jornada escolar e a concepção de educação integral adotada.

Para que a escola em tempo integral ofereça educação integral, no sentido de um amplo espectro de aprendizagens (estéticas, corporais, cidadãs, cognitivas, etc.), como preconizava Anísio Teixeira (2004), é necessária uma nova organização do trabalho pedagógico, ou seja, reflexões sobre dimensões pedagógicas e organizacionais da escola.

Por isso, é plausível que, nos estudos anteriormente citados, os autores apontem, na análise dos seus resultados, questões sobre a articulação curricular e as condições estruturais das escolas (CASTRO; LOPES, 2011; SOUZA, 2015); a 
questão do trabalho docente, isto é, ausência de professores, carga horária insuficiente para atuação no tempo integral (CASTRO; LOPES, 2011); a qualidade da aula e a mobilização do estudante para o aprender (SOUZA, 2015); a abertura da escola e as parcerias com propostas que não têm o currículo escolar como centrais em sua proposição (COELHO, 2012).

Encontrar um modo de analisar esse amplo espectro em suas especificidades não é tarefa simples. Talvez, por isso, essa seja ainda uma questão pouco estudada no tempo integral brasileiro, lacuna apontada na literatura da área (BRASIL, 2010a; COELHO, 2012; MAURÍCIO, 2014). Considerando esse leque de aspectos a ser contemplado, a próxima seção deste artigo tenciona apresentar um modelo de qualidade da escola em tempo integral, desenvolvido por Heinz Günter Holtappels para sistematizar possíveis critérios para avaliar a sua qualidade.

\section{CRITÉRIOS DA QUALIDADE DA ESCOLA EM TEMPO INTEGRAL}

Colocar em pauta a questão da qualidade da educação da escola em tempo integral é, igualmente, discutir sobre quais critérios podem ser utilizados para avaliar as propostas de educação em tempo integral, seja em termos macro de política educacional, seja em termos de qualidade de uma escola específica. Tanto em termos macro como em termos micro, é preciso definir o que se entende por qualidade (DOURADO; OLIVEIRA, 2009; GADOTTI, 2013).

Dourado e Oliveira (2009) ressaltam a polissemia do termo "qualidade", que contém conotações históricas, pois o que se compreende como qualidade da educação ou educação de qualidade depende do contexto no qual se determina a função social da escola e o que se espera da educação. Tomando como referência a literatura já discutida sobre a ampliação da jornada escolar, a qualidade da escola em tempo integral, em termos micro, pressupõe uma escola que, além da aquisição de competência de conteúdos cognitivos, também garanta a aprendizagem em uma perspectiva multidimensional. Nesse sentido, para avaliar a qualidade de uma 
escola, exige-se a definição do que se compreende como qualidade, ou seja, quais critérios e características da escola precisam ser avaliados.

Vale ressaltar que as escolas em tempo integral podem ser avaliadas conforme critérios estabelecidos também para escolas de tempo parcial, contudo, faz-se necessário acrescentar outros critérios, em razão da multidimensionalidade da educação integral em tempo integral. A escolha de critérios de qualidade da educação escolar, seja ela em tempo parcial ou integral, pode se basear em argumentos educacionais teóricos que abordam, por exemplo, as novas funções da escola e a relação entre escola e sociedade, como discutido inicialmente.

Também é possível utilizar critérios propostos por pesquisas anteriores, decorrentes do conhecimento científico empírico já adquirido. As características que marcam escolas bem-sucedidas, como revelam estudos empíricos na área da School Effectiveness Research, são: competência de liderança da gestão relacionada ao ensino; gestão participativa e responsabilidade compartilhada, inclusive com os alunos; participação das pessoas envolvidas nos processos educacionais; abertura para parcerias, principalmente com os pais e responsáveis; ambiente seguro, que dá suporte para a aprendizagem; orientação no desempenho e expectativas altas; visão compartilhada de objetivos e ensino centrado nesses objetivos; uso de resultados de avaliações para o desenvolvimento organizacional do ensino; monitoramento do processo de aprendizagem e feedback; currículos equilibrados (ou seja, relação adequada entre aquilo que está sendo ensinado e aquilo que está sendo avaliado em testes) e atenção (ao nível da escola) para abordagens didáticas específicas, tanto disciplinares como interdisciplinares; bem como o desenvolvimento pessoal dos profissionais que atuam na escola (SAMMONS et al., 1995; SCHEERENS, 2013).

A qualidade da escola em tempo integral pode ser medida conforme esses mesmos critérios de qualidade propostos para as escolas de tempo parcial. Mas, por se esperar da escola em tempo integral uma oferta pedagógica diferenciada, e não apenas um desempenho similar, como afirmado anteriormente, 
10 Documentos disponíveis em: $<$ http://educacaointegral.mec.gov br/>. Acesso em: 23 nov. 2015 ainda é preciso adotar outros critérios que levem em conta suas características específicas. Essas características específicas também dependem de argumentos educacionais teóricos e empíricos específicos, nos quais se baseiam expectativas associadas à escola em tempo integral, como vimos acima, e dependem da própria definição normativa sobre o que se compreende como escola em tempo integral. Essa normatização se refere às características estruturais e formais.

Em uma perspectiva normativa, algumas características formais e estruturais da escola em tempo integral no Brasil encontram-se especificadas em diferentes documentos publicados pelo MEC sobre a educação integral, disponíveis em seu site. ${ }^{10}$ Pode se depreender, da leitura desses documentos, que a escola em tempo integral tem como especificidades a considerar: o uso de espaços não escolares para realização de atividades organizadas pela escola; a abertura da escola para pessoas da comunidade com saberes e experiências que podem ser incorporados ao tempo escolar; a articulação entre o ensino em sala de aula e a oferta extraclasse; o acompanhamento pedagógico, realizado por docentes ou pessoal não escolar como, por exemplo, estudantes de graduação em formação; e a alimentação escolar com vistas à educação alimentar; entre outros.

Em outras palavras, avaliar a qualidade da escola em tempo integral também significa avaliar o quanto as atividades organizadas pela escola são articuladas entre si, o quanto o diagnóstico do potencial do aluno pela escola levou a uma diferenciação no seu acompanhamento pedagógico, o quanto a escola conseguiu incluir, no quadro de colaboradores, pessoas com formação ou conhecimento específicos para adequar a oferta em tempo integral à demanda (e ao interesse) do aluno, o quanto reorganizou os espaços para atender adequadamente os estudantes (laboratórios, ateliês, salas de aula, espaços para lazer e atividades físicas, espaços para alimentação e higiene pessoal). Implica, também, uma avaliação da abertura da escola para assuntos comunitários, criação de parcerias e aproveitamento de espaços comunitários para a realização de atividades.

Nota-se que a avaliação da qualidade da escola em tempo integral não apenas se refere a mudanças em âmbito 
pedagógico, mas também em âmbito organizacional. Diante da complexidade do desafio pedagógico e organizacional para a análise da qualidade da escola em tempo integral, o uso de um modelo parece uma ferramenta útil para sistematizar o desenvolvimento institucional de uma escola de tempo parcial para uma escola em tempo integral.

Recorre-se, aqui, a modelos teórico-empíricos da qualidade da escola, discutidos por Holtappels (2009) para enriquecer a reflexão sobre pesquisa e práticas também da educação em tempo integral. O autor considera a análise de Scheerens e Bosker (1997 ${ }^{11}$ apud HOLTAPPELS, 2009) como um dos trabalhos mais bem fundamentados sob o ponto de vista empírico e teórico para sistematizar a qualidade da escola.

O modelo de Scheerens e Bosker distingue a avaliação em três níveis: no nível macro se avalia a qualidade do input (condições do sistema educacional, políticas educacionais, disponibilização de diretrizes e recursos), no nível meso, a qualidade de processos (configuração/organização pedagógica da escola e seus processos pedagógicos), e no nível individual, a qualidade do output (resultados dos alunos, ou seja, competências, atitudes, disposições), considerando que esses três níveis fazem parte de determinado contexto social (condições de socialização, meios sociais, recursos dos arredores; networking entre escolas, etc.).

O foco deste texto é a dimensão dos processos em nível meso, ou seja, no nível da escola. No que diz respeito às características referentes a decisões sobre organização e configuração do trabalho pedagógico da escola, é possível listar, consequentemente, critérios referentes tanto à estrutura e cultura da organização como à cultura da aprendizagem.

No que diz respeito à estrutura organizacional, cabem, conforme Holtappels (2009), valores, objetivos e normas, por exemplo, visão, missão, filosofia educacional, regras, orientações pedagógicas; o clima de inovação e a disposição de empreender inovações; a organização do tempo, ou seja, o novo ritmo do dia escolar; a organização e configuração de espaços; a organização do trabalho pedagógico e processos educacionais (diferenciação interna, formação de grupos de estudos); a compreensão de gestão e formas de liderança; a
11 SCHEERENS, J.; BOSKER, R. The foundations of educational effectiveness. Oxford, New York; Tokyo: Elsevier Science, 1997. 
12 HELMKE, A. Unterricht erfassen bewerten, verbessern [Diagnosticar avaliar e melhorar o ensino em sala de aula]. Selse: Friedrich Verlag, 2003 organização e gestão de pessoas; o trabalho em equipe e a cooperação do pessoal; o clima de trabalho e a colegialidade; as exigências e as jornadas de trabalho do professor; o contato entre escola e pais/responsáveis; a cooperação com parceiros externos da escola; e a imagem da escola.

Referente à cultura de aprendizagem e à cultura da educação cidadã, é possível listar critérios como as oportunidades de aprendizagem e a oferta pedagógica (por exemplo, projetos extraclasse que abrangem mais que uma turma); a infraestrutura e equipamentos (por exemplo, refeitório, biblioteca, aconselhamento escolar); a participação dos alunos em processos de tomada de decisão e em espaços decisórios da escola; a participação dos pais/responsáveis; e o clima social da escola.

Além disso, cabem, no nível meso, os processos que ocorrem dentro de turmas e grupos de estudos, ou seja, a cultura de processos de ensino-aprendizagem. A cultura da aprendizagem descreve concepções de ações e possibilidades de aprendizagem que a escola oferta. Abrange aqui os aspectos do conteúdo curricular (orientação no contexto da vida do aluno, orientação em parâmetros curriculares de ensino), da didática e do método (diferenciação e variabilidade de arranjos de aprendizagem); a atuação e as disposições dos professores e educadores (exigências de desempenho adequadas, avaliação educacional adequada, engajamento em acompanhamento individualizado); e a qualidade dos processos de ensino. Fazem serventia aqui, por exemplo, as características da qualidade do ensino de Helmke (2003 ${ }^{12}$ apud HOLTAPPELS, 2009). Quanto às disposições e atuação do corpo docente, destacam-se engajamento, motivação, autorreflexão, etc.; as perícias científicas da área de conhecimento deles; as suas perícias referentes à didática (clareza, estruturação, compreensibilidade, diversidade metodológica, individualização); as suas perícias diagnósticas e a qualidade de motivação (promoção de motivação, colocação adequada de exigências, tempo); a gestão de sala de aula (disciplina, feedback para aluno); a quantidade de ensino (tempo de ensino, tempo de aprendizagem, disponibilidade de tempo de ensino em sala de aula, uso efetivo do tempo de aprendizagem); 
qualidade do material didático; como também as condições contextuais do ensino em sala de aula.

Esses critérios, assim vale ressaltar, se referem a todos os processos educacionais da escola, não só àqueles que ocorrem nas aulas regulares, mas também aos processos educacionais que ocorrem além do ensino regular, ministrados pelo pessoal não escolar, como em muitas propostas de tempo integral no Brasil.

Também vale destacar a importância de que a escola reconheça a combinação sinérgica de atuação de fatores, ou seja, não são preponderantes os fatores individuais, mas a sua combinação. Dessa forma, um desenvolvimento organizacional da escola de tempo parcial para uma escola em tempo integral considera a interligação entre a dimensão de condições estruturais, a dimensão dos processos organizacionais e de processos pedagógicos.

No que diz respeito à qualidade do sistema (diretrizes estruturais, recursos, competências profissionais, cooperações locais, tipos de escolas, sistemas de apoio), influencia tanto a qualidade do processo de organização pedagógica (concepções conceituais, organização do tempo, orientação em objetivos, disposição à inovação, cooperação interna, liderança, gestão e desenvolvimento de pessoas, etc.), como também a dimensão da qualidade dos resultados/output I (a intensidade da participação, o perfil dos participantes, composição do alunado em determinadas ofertas, entre outros).

Ao mesmo tempo, influencia a qualidade do processo da organização pedagógica também a qualidade dos processos pedagógicos (classroom management, acompanhamento individual, estruturação e adaptabilidade do ensino em sala de aula, e estrutura das atividades extraescolares, orientação em tarefas ativas e competências, clima de aprendizagem, entre outros).

A qualidade dos processos pedagógicos e a qualidade do output I se influenciam mutuamente e ambos influenciam os resultados em outro nível (output II: competências de conteúdos do aluno, suas estratégias de aprendizagem, suas disposições de aprendizagem e disposições sociopsicológicas, seu comportamento social e seu grau de formação alcançado). 
A qualidade desses resultados (output II) e dos processos pedagógicos depende também do contexto social (status socioeconômico do aluno, apoio familiar, etc.).

Dessa forma, a escola precisa compreender que a dedicação empregada na realização de apenas um ou outro desses fatores não é suficiente para garantir a qualidade da educação ofertada, assim como a própria pesquisa sobre a educação em tempo integral tem de levar em conta que esses fatores organizacionais e os fatores do processo de ensino e aprendizagem não agem de forma isolada, e investigações científicas precisam reconhecer que eles se influenciam. Soares (2012) alerta que não é possível tratar da qualidade da educação sem considerar os diferentes níveis envolvidos. Um modelo precisa abordar esses diversos níveis que, embora articulados, possuem características próprias: "os alunos, a sala de aula, a escola, as redes e a sociedade" (SOARES, 2012, p. 236).

A questão da qualidade de programas em tempo integral é objeto da publicação intitulada Percursos da Educação Integral: em busca da qualidade e da equidade (LOMONACO, 2013), que dedica um capítulo específico sobre a temática da qualidade e sua relação com a avaliação. As discussões destacam a necessidade de monitoramento e avaliação do tempo integral, e apresentam experiências de diferentes municípios nesse sentido. Uma análise dessas experiências mostra as tentativas de avaliação contemplando aspectos diversos: gestão da escola, articulação da proposta no território, formação e condições de trabalho, práticas educativas, infraestrutura e condições materiais, acesso e permanência, convívio e interações. Podemos encontrar nessas experiências de avaliação a presença das características de qualidade da escola, conforme proposto por Holtappels (2009). Entretanto, nessas experiências, sobressai-se uma ou outra caraterística, e é nesse sentido que o modelo aqui apresentado pode contribuir para o estabelecimento de critérios para a qualidade da escola em tempo integral e, como consequência, como balizador para a avaliação da eficácia escolar.

Por sua vez, no campo da pesquisa educacional, os estudos realizados de modo mais amplo no Brasil sobre ampliação 
da jornada escolar (BRASIL, 2010a; BRASIL, 2010b) contribuíram decisivamente para a visibilidade das propostas em tempo integral, analisadas sob diferentes aspectos: número de alunos atendidos, modalidade de oferta (turno ou contraturno), currículo, disponibilidade docente, espaços educativos, número de horas ampliadas, condições das escolas, diálogos com a comunidade, ações intersetoriais, entre outros aspectos. Contudo, o objetivo dos estudos foi o de mapear essas propostas e apresentar um panorama da educação em tempo integral no país. Portanto, há ainda um campo aberto de estudos na avaliação das propostas em tempo integral, principalmente avaliações da eficácia da escola em tempo integral e seus impactos.

Para isso, são necessários estudos de múltiplas perspectivas que abrangem diversas variáveis a serem analisadas, principalmente a perspectiva dos usuários, ou seja, dos alunos e pais/responsáveis, pois, conforme Helmke (2003 apud HOLTAPPELS, 2009), a eficácia da oferta depende tanto do fato de como os alunos percebem, operam e interpretam as expectativas do professor/educador e os processos pedagógicos e, por outro lado, quais processos motivacionais, sociais, emocionais e volitivos ocorrem com o corpo discente, considerando que o proveito das oportunidades de aprendizagem é influenciado também pelo perfil do aluno e pelo seu contexto social.

Para poder, acima de tudo, observar tendências, identificar condições favoráveis e desfavoráveis para a implementação e operacionalização da educação em tempo integral e do desenvolvimento organizacional da escola, e medir os seus efeitos na aprendizagem do aluno e demais impactos da jornada escolar ampliada, recomenda-se, além disso, pesquisas quantitativas e qualitativas com desenho operacional não só de multiníveis, mas também de natureza longitudinal. Com efeito, para avaliar a aprendizagem do corpo discente, não é suficiente medir desempenhos transversalmente em momentos diferentes de diferentes alunos, mas é preciso comparar os desempenhos (em diversos campos de conhecimento) do mesmo aluno, medidos, em diversos momentos, em um período maior. 


\section{CONSIDERAÇÕES FINAIS}

As reflexões empreendidas neste texto tiveram como propósito ampliar o debate sobre o tempo integral, com o argumento de que o tempo a mais na escola só tem sentido se propiciar a aprendizagem do aluno.

Embora a escola se constitua como uma instituição que integra uma rede protetora infanto-juvenil, possui a tarefa específica de ensinar, transmitir às novas gerações saberes historicamente consolidados e propiciar o desenvolvimento de competências e habilidades, que favoreçam o acesso não só a níveis posteriores de ensino e ao mercado de trabalho mas, também, à cultura, respondendo a demandas pessoais e coletivas. Por isso, espera-se que a escola em tempo integral propicie a aprendizagem em uma perspectiva multidimensional, mais do que proteção e cuidados ou uma função propedêutica de preparação para a vida futura.

Por se tratar de educação integral em tempo integral, a defesa é que se aliem às tradicionais disciplinas escolares aprendizagens estéticas, culturais e cidadãs. Desse modo, o debate sobre o tempo integral nesses últimos anos contribui para um repensar sobre a função da escola enquanto instituição formadora.

É, pois, nesse sentido, que não se pode efetivamente medir os efeitos do tempo integral somente pelos resultados do Ideb ou pela ampliação do número de estudantes matriculados, ou, ainda, pelo enriquecimento da oferta escolar com atividades socioculturais. Há que se considerar o amplo espectro das aprendizagens que constituem o tempo integral e a competência da escola em efetivamente promovê-las.

É possível, como vimos, conforme Holtappels (2009), sistematizar os seguintes objetivos norteadores do âmbito pedagógico da escola em tempo integral: desenvolver uma nova cultura de ensino e aprendizagem, caracterizada por uma diferenciação interna; ofertar um acompanhamento individualizado para o aluno; ampliar as oportunidades de aprendizagem nas disciplinas, mas também promover aprendizagens inter e transdisciplinares, orientadas nos interesses e talentos dos alunos; proporcionar a aprendizagem sociocultural em comunidade; possibilitar que o aluno participe 
e interaja democraticamente; abrir a escola para a vida social na comunidade e contextualizar o ensino; ofertar atividades lúdicas, de lazer e de pedagogia de mídia.

Em prol do desenvolvimento organizacional de uma escola em tempo integral de qualidade, é preciso dar ênfase a alguns aspectos, tais como a abertura institucional da escola; a participação de alunos e seus pais/responsáveis em processos decisórios; a organização e configuração de espaços (escolares e não escolares); a concepção de alimentação/ nutrição; a configuração do dia escolar e o seu novo ritmo; e, consequentemente, a gestão e formação do pessoal multiprofissional, bem como a cooperação entre eles.

Recomenda-se não apenas apostar em um desses objetivos pelo fato de análises empíricas mostrarem que não só os fatores isolados são decisivos, mas em razão da combinação de fatores atuando sinergicamente (HOLTAPPELS, 2009).

Ao apresentarmos, neste texto, as contribuições de Holtappells, que propôs um modelo de qualidade da escola em tempo integral, salientamos que esse modelo pode contribuir como norteador para o desenvolvimento organizacional da escola em tempo integral. Pode-se depreender que esse modelo contribui, também, como ferramenta heurística para atribuir determinados critérios de avaliação do tempo integral. Para tal, faz-se necessário, em um primeiro momento, definir o que se compreende por uma "boa" escola em tempo integral, ou seja, definir os critérios da sua qualidade. Consequentemente, esses critérios podem se tornar, posteriormente, indicadores que contribuam para estabelecer parâmetros para a avaliação da escola em tempo integral.

Como desafios impostos a gestores de políticas educacionais, destacam-se um repensar da escola em termos meso, como os critérios anteriormente elencados apontaram, e a elaboração de mecanismos efetivos para o monitoramento e a avaliação da qualidade pretendida com a ampliação da jornada escolar.

Ressalta-se que, após oito anos da proposição do Programa Mais Educação como indutor de políticas em tempo integral no Brasil e das propostas de tempo integral, que se multiplicam no país, faz-se urgente e necessária a análise 
sobre a eficácia da escola em tempo integral e sobre os impactos da ampliação do tempo para a melhoria da qualidade da educação. Apontamos neste artigo algumas possibilidades de articulação entre aprendizagem, qualidade e avaliação da qualidade das experiências da educação em tempo integral. Certamente, dada a escassez de pesquisas, esse é um campo fértil para estudos, cuja necessidade se coloca pelo compromisso político de pesquisadores com a educação.

\section{REFERÊNCIAS}

BRANCO, Veronica. Desafios para a implantação da educação integral: análise das experiências desenvolvidas na região sul do Brasil. Educar em revista, n. 45, p. 111-123, 2012. Disponível em: <http://www.scielo.br/pdf/er/ n45/08.pdf>. Acesso em: 6 mar. 2015.

BRASIL. Constituição da República Federativa do Brasil. Brasília, DF: Senado, 1988.

BRASIL. Lei n. 8.069, de 13 de julho de 1990. Dispõe sobre o Estatuto da Criança e do Adolescente e dá outras providências. Diário Oficial da República Federativa do Brasil, Brasília, DF, 16 jul. 1990.

BRASIL. Lei n. 9.394, de 20 de dezembro de 1996. Estabelece as diretrizes e bases da educação nacional. Diário Oficial da República Federativa do Brasil, Brasília, DF, 23 dez. 1996.

BRASIL. Lei n. 11.494, de 20 de junho de 2007. Dispõe sobre o Fundo de Desenvolvimento da Educação Básica e de Valorização dos Profissionais da Educação. Diário Oficial da União, Brasília, DF, 22 jun. 2007a.

BRASIL. Decreto n. 6.253, de 13 de novembro de 2007. Dispõe sobre o Fundo de Manutenção e Desenvolvimento da Educação Básica e de Valorização dos Profissionais da Educação - FUNDEB, regulamenta a Lei n. 11.494, de 20 de junho de 2007, e dá outras providências. Diário Oficial da União, Brasília, DF, 14 nov. 2007b.

BRASIL. Portaria Interministerial n. 17, de 24 de abril de 2007. Institui o Programa Mais Educação que visa fomentar a educação integral de crianças, adolescentes e jovens, por meio do apoio a atividades sócio-educacativas no contraturno escolar. Diário Oficial da República Federativa do Brasil, Brasília, DF, 26 abr. 2007c.

BRASIL. Ministério da Educação. Educação integral/educação integrada e(m) tempo integral: concepções e práticas na educação brasileira. Mapeamento das experiências de jornada escolar ampliada no Brasil: estudo quantitativo. Brasília, DF: MEC, 2010a. Disponível em: <http://portal.mec.gov.br>. Acesso em: 5 maio 2015.

BRASIL. Ministério da Educação. Educação integral/educação integrada e(m) tempo integral: concepções e práticas na educação brasileira. Mapeamento das experiências de jornada escolar ampliada no Brasil: estudo qualitativo. Brasília, DF: MEC, 2010b. Disponível em: <http:/|portal.mec.gov.br>. Acesso em: 5 maio 2015. 
BRASIL. Ministério da Educação. Programa Mais Educação: impactos na educação integral e integrada. Brasília, DF: MEC, 2013a.

BRASIL. Ministério da Educação. Secretaria de Educação Básica. Diretrizes Curriculares Nacionais para a Educação Básica. Brasília, DF, 2013b.

BRASIL. Ministério da Educação. Secretaria de Educação Básica. Diretoria de Currículos e Educação Integral. Manual Operacional de Educação Integral. Brasília, DF, 2014a. Disponível em: <portal.mec.gov.br/index.php>. Acesso em: 19 dez. 2014.

BRASIL. Lei n. 13.005, de 25 de junho de 2014. Aprova o Plano Nacional de Educação - PNE e dá outras providências. Diário Oficial da União, Brasília, DF, 26 jun. 2014b.

BRASIL. Portaria n. 174, de 13 de maio de 2015. Dispõe sobre o Sistema de Avaliação da Educação Básica - Saeb. Diário Oficial da União, Brasília, DF, 14 maio 2015.

BRESSOUX, Pascal. Efeito estabelecimento. In: ZANTEN, Agnés van. Dicionário de Educação. Petrópolis: Vozes, 2011, p. 273-279.

CASTRO, Adriana de; LOPES, Roseli Esquerdo. A escola de tempo integral: desafios e possibilidades. Ensaio: Avaliação e Políticas Públicas em Educação, Rio de Janeiro, v. 19, n. 71, p. 259-282, abr./jun. 2011.

CAVALIERE, Ana Maria. Tempo de escola e qualidade na educação pública. Educação \& Sociedade, v. 28, n. 100, p. 1.015-1.035, 2007. Disponível em: <http:/ www.scielo.br/pdf/es/v28n100/a1828100.pdf>. Acesso em: 6 mar. 2015.

CAVALIERE, Ana Maria. Escolas de tempo integral versus alunos em tempo integral. Em aberto, Brasília, DF, v. 22, n. 80, p. 51-63, abr. 2009.

COELHO, Lígia Martha C. da Costa. História(s) da educação integral. Em aberto, Brasília, DF, v. 22, n. 80, p. 83-96, abr. 2009a.

COELHO, Lígia Martha C. da Costa (Org.). Educação integral em tempo integral: estudo e experiências em processo. Rio de Janeiro: FAPERJ, 2009b.

COELHO, Lígia Martha C. da Costa. Alunos no ensino fundamental, ampliação da jornada escolar e educação integral. Educar em Revista, Curitiba, n. 45 , p. 73-89, jul./set. 2012.

COELHO, Lígia Martha C. da Costa; CAVALIERE, Ana Maria Villela (Org.). Educação brasileira e(m) tempo integral. Petrópolis, Vozes, 2002.

CORÁ, Elsio José; LOSS, Adriana Salete; BEGNINI, Sérgio (Org.). Contribuições da UFFS para educação integral em jornada ampliada. Chapecó, 2012.

DOURADO, Luiz Fernandes; OLIVEIRA, João Ferreira de. A qualidade da educação: perspectivas e desafios. Cadernos Cedes, Campinas, v. 29, n. 78, p. 201-215, maio/ago. 2009. Disponível em: <http://www.cedes.unicamp.br>. Acesso em: 17 out. 2015.

FUNDAÇÃO ITAÚ SOCIAL. Survey da literatura sobre educação integral. São Paulo, 2015a. Disponível em: <http://www.redeitausocialdeavaliacao.org.br/>.

Acesso em: 25 nov. 2015. 
FUNDAÇÃO ITAÚ SOCIAL. Programa Mais Educação: avaliação de impacto e estudo qualitativo. São Paulo, 2015b. Disponível em: <http:/ educacaointegral.org.br/wp-content/uploads/2015/10/pesquisa-feita-peloBanco-Mundial-em-parceria-com-a-Funda\%C3\%A7\%C3\%A3o-Ita\%C3\%BA-Social. pdf>. Acesso em: 25 nov. 2015.

FUNDAÇÃO ITAÚ SOCIAL; FUNDO DAS NAÇÕES UNIDAS PARA A INFÂNCIA. Educação integral. Cadernos Cenpec: pesquisa e ação educacional, São Paulo, v. 1, n. 2, 2006.

FUNDAÇÃO ITAÚ SOCIAL; FUNDO DAS NAÇÕES UNIDAS PARA A INFÂNCIA. Tendências para educação integral. São Paulo: UNICEF; CENPEC, 2011.

GADOTTI, Moacir. Qualidade na educação: uma nova abordagem. In: CONGRESSO DE EDUCAÇÃO BÁSICA: QUALIDADE NA EDUCAÇÃO BÁSICA, 2013. Florianópolis. Anais... Florianópolis: COEB/Rede Municipal de Ensino de Florianópolis, 2013. Disponível em: <http://www.pmf.sc.gov.br/arquivos/ arquivos/pdf/14_02_2013_16.22.16.85d3681692786726aa2c7daa4389040f. pdf>. Acesso em: 23 nov. 2015.

GADOTTI, Moacir. Educação integral no Brasil: inovações em processo. São Paulo: Instituto Paulo Freire, 2009.

HOLTAPPELS, Heinz Günther. Qualitätsmodelle: Theorie und Konzeptionen [Modelos de qualidade: teoria e concepções]. In: KAMSKI, Ilse; HOLTAPPELS, Heinz Günter; SCHNETZER, Thomas. Qualität von Ganztagsschule: Konzepte und Orientierungen für die Praxis. Münster: Waxmann, 2009. p. 11-25.

LOMONACO, Beatriz Penteado; SILVA, Letícia Araújo Moreira da. Percursos da educação integral em busca da qualidade e da equidade. São Paulo: Fundação Itaú Social, 2013.

MAURÍCIO, Lúcia V. Ampliação da jornada escolar: configurações próprias para diferentes contextos - Brasil e Europa. Ensaio: Avaliação e Políticas Públicas em Educação, Rio de Janeiro, v. 22, n. 85, p. 875-898, out./dez. 2014.

MOLL, Jaqueline et al. Caminhos da educação integral no Brasil: direito a outros tempos e espaços educativos. Porto Alegre: Penso, 2012.

PARO, Vitor Henrique. Educação Integral em tempo integral: uma concepção de educação para a modernidade. In: COELHO, Lígia Martha. C. C. (Org.). Educação integral em tempo integral: estudo e experiências em processo. Rio de Janeiro: FAPERJ, 2009. p. 13-20.

ROLLETT, W. Escola em tempo integral na Alemanha: ampliação e consolidação, justificativa baseada em argumentos político-educacionais e fundamentos teóricos. In: SEMINÁRIO NACIONAL DE POLÍTICA E GESTÃO DA EDUCAÇÃO, 3.; ENCONTRO INTERNACIONAL DE PESQUISA EMPÍRICA EM EDUCAÇÃO, TEMA: A ESCOLA EM TEMPO INTEGRAL, 1., 2014, São Cristóvão, Sergipe. Anais eletrônicos.... São Cristóvão, SE: Universidade Federal de Sergipe; Grupo de Pesquisa em Avaliação, Política, Gestão e Organização da Educação, 2014a, p. 10-21. Disponível em: <http://apogeu. ufs.br/sites/default/files/42/caderno_de_trabalhos_apogeu_2014.pdf>. Acesso em: 15 ago. 2015. 
SAMMONS, Pam et al. Key characteristics of effective schools: a review of school effectiveness research. London: Institut of Education, 1995. Disponível em: <http://files.eric.ed.gov/fulltext/ED389826.pdf>. Acesso em: 27 ago. 2015.

SCHEERENS, Jaap. Wodurch zeichnen sich gute Schulen aus? [O que distingue escolas boas?]. Entrevista realizada por Thomas Riecke-Baulecke. Schulmanagement, München, v. 3, p. 22-24, dez. 2013.

SOARES, José Francisco. Qualidade da educação. In: DAYRELL, Juarez et al. (Org.). Familia, escola e juventude: olhares cruzados Brasil-Portugal.

Belo Horizonte: Editora da UFMG, 2012. p. 231-254.

SOUZA, Maria Celeste Reis Fernandes de. Relação com o saber e educação integral: um estudo sobre estudantes dos anos finais do ensino fundamental no contexto da escola em tempo integral. 248f. Relatório de Pesquisa (Pós-Doutorado em Educação) - Programa de Pós-Graduação em Educação, Universidade Federal de Sergipe, Aracaju, 2015.

TEIXEIRA, Anísio. Educação é um direito. 3. ed. Rio de Janeiro: UFRJ, 2004.

UNIVERSIDADE FEDERAL DE MINAS GERAIS - UFMG. Faculdade de Educação. Grupo Teia - Territórios, Educação Integral e Cidadania. Relatório do Projeto de Avaliação e Monitoramento do Programa Escola de Tempo Integral (ETI) da Secretaria Municipal de Educação de Governador Valadares - MG.

Belo Horizonte, 2012, 128 p.

\section{HEIKE SCHMITZ}

Professora adjunta do Departamento de Educação e do Programa da Pós-Graduação em Educação da Universidade Federal de Sergipe (UFS), São Cristóvão, Sergipe, Brasil. Líder do Grupo de Pesquisa em Avaliação, Política, Gestão e Organização da Educação (Apogeu) hs.contato.ufs@gmail.com

\section{MARIA CELESTE REIS FERNANDES DE SOUZA}

Professora do Programa de Pós-Graduação em Gestão Integrada do Território da Universidade do Vale do Rio Doce (Univale), Governador Valadares, Minas Gerais, Brasil. Vinculada aos grupos de pesquisa Núcleo Interdisciplinar de Educação, Saúde e Direito (Niesd/Univale) e Educação e Contemporaneidade (EDUCON/UFS)

celeste.br@gmail.com 